\title{
REPEATABILITY AND REPRODUCTION ACCURACY IN ELECTROPHOTOGRAPHY FOR COLOR DIFFERENCE EVALUATIONS
}

\author{
Sandra Dedijer (D), Ivana Tomić (D), Magdolna Pál (iD), \\ Ivana Jurič (D), Živko Pavlović (D), Neda Milić (iD) \\ University of Novi Sad, Faculty of Technical Sciences, \\ Department of Graphic Engineering and Design, Novi Sad, Serbia
}

\begin{abstract}
In this paper, we have investigated the applicability of electophotography, in terms of repeatability and reproduction accuracy, for color difference evaluations. When performing color difference evaluations with printed samples, the printing technique used may more or less influence the color reproduction. In order to evaluate the influence of reproduction accuracy and short term repeatability in electrophotography on color difference evaluation, we chose to examine the color reproduction of five initial color centers which were varied in their lightness. For color difference calculation we used CIE2000 color difference formula. It was shown that the expected color differences were not obtained in all cases and for all colors used whereas the variability is not only influenced by the color center but also by the level and direction of lightness variation.
\end{abstract}

Key words: electrophotography, color difference, CIEOO

\section{INTRODUCTION}

Evaluation of color can be performed through instrumental, objective assessment of color stimuli, or visual, subjective one based on human color perception (Brainard, 2003; Gulrajani, 2010; Fairchild, 2013).

The objective color analysis usually encompasses the examination of the color differences between various colored stimuli using appropriate color difference equations such as CIELAB (CIE76), CIELUV, CMC, BFD, CIE94, CIEOO (Xin et al, 2001; Xu, Yaguchi et al, 2002; Hong et al, 2006; Ho et al, 2004; Laborie et al, 2010). In the graphic industry, color difference is usually calculated using CIE76, CIEO0 or CMC formula. Each of them performs best under a specific, more or less unique set of reference conditions whereas different results might, in some color regions, be quite significant (Xin et al, 2001). CIE94 ( $\left.\Delta \mathrm{E}_{94}\right)$ and CIEO0 ( $\left.\Delta \mathrm{E}_{00}\right)$ are two, so called advanced formulae, are tended to adjust the numerical expression of difference to the way human observers perceive differences depending on the location of the color in color space and its intensity introducing the weighting factors into basic equation $\left(\Delta E_{a b}\right)$. These equations are highly recommended for use with color-differences in the range of 0.0 to $5.0 \Delta \mathrm{E}$ units for prints and textile (Ho et al, 2004; SpectraCal, 2018). The previous research has proven that CIEOO have a strong agreement with human perception in regards to lightness, chroma and hue of the tested colors (Mangine et al, 2005; Pant et al, 2010; Ortiz-Jaramillo et al, 2016; Pant et al, 2012; SpectraCal, 2018).

Color difference calculations are usually performed between target color stimuli and corresponding reproduced match. The pass/fail decision is generally made on the basis of the established color difference threshold which will differ in $\Delta E$ value depending upon the area of application and color difference formulae used: a difference of $5 \Delta \mathrm{E}$ may be acceptable in some applications, whereas for other, differences over $1 \Delta \mathrm{E}$ may be unacceptable (Dedijer et al, 2017).

In the graphic arts and printing industry, for most demanding works, the maximum acceptable $\Delta \mathrm{E}$ color difference is $1.5 \Delta \mathrm{E}$. According to ISO standard for offset printing, tolerances are even more stretched (ISO 12647-2:2013): up to $5 \Delta \mathrm{E}_{\mathrm{ab}}$ for Cyan, Magenta, Yellow and Black or $3.5 \Delta \mathrm{E}_{00}$ (perceptual assessments) for Cyan, Magenta, Yellow and 5.0 for Black.

In digital printing, according to IDEAlliance Digital Press Certification Program, it is suggested that in color difference evaluation CIEOO equation should be used whereas color difference of $5 \Delta E_{00}$ should not be exceeded through all the patches of the Digital Press Control Strip 2011. Tolerances for the short term and long term repeatability for the primary and secondary colors should not exceed color difference value of 3 (Ideaaliance, 2018).

In color differences evaluation, where a series of color tests are to be compared with a color reference, influence of printing technology should be omitted or at least minimal and known and taken into consideration. 
In this research, we have investigated the possibilities of using electrophotography, digital printing technique, for the purpose color difference evaluation. We have aimed to preliminary establish to which extend the used printing technique alter the targeted color difference. We have been driven with general recommendations of the IDEAlliance certification program for electrophotography printing technique.

\section{MATERIALS AND METHODS}

In order to evaluate the level of reproduction inconsistency which will be directly influenced by the printing technique used, we chose five initial color centre (Xu et al, 2002)(Table 1). Their lightness of samples was varied in the steps of $\Delta \mathrm{E} 0.5$, where the changes were made in both directions: by lowering and increasing the value. The smallest color difference from the initial color was 0.5 , while the largest was set to be 5 . We created one color test chart (Figure 1) with all five colors and all color patches with targeted color difference values. The targeted digital $\mathrm{L}, \mathrm{a}, \mathrm{b}$ data of each color patch were calculated on the basis of expected color difference value $\Delta E_{a b}, L, a$, and $b$ values of five initial color centres and following formulae (Gulrajani, 2010; Fairchild, 2013, Stone et al, n.d.):

$\Delta \mathrm{E}_{a b}$ color difference: $\Delta \mathrm{E}_{a b}=\sqrt{\left[\Delta \mathrm{L}^{2}+\Delta \mathrm{a}^{2}+\Delta \mathrm{b}^{2}\right]}$

where:

$\Delta \mathrm{L}$ - the lightness difference: $\Delta \mathrm{L}=L_{1}-L_{2}$,

$\Delta \mathrm{a}$ and $\Delta \mathrm{b}$ - chromaticity differences: $\Delta \mathrm{a}=a_{1}-a_{2}, \Delta \mathrm{b}=b_{1}-b_{2}$,

$L_{1}, a_{1}, b_{1}$ - lightness and chromaticity coordinates of sample 1 (CIE color centre); $L_{2}, a_{2}, b_{2}$ - lightness and chromaticity coordinates of sample 2 (targeted color patch).

The $L, a, b$ data were then recalculated to RGB values (CIE D50 standard illuminant and standard $2^{\circ}$ observer; 0-1 scale) and used for of the generation of color patches size of $2 \times 2 \mathrm{~cm}$ (sRGB, tiff format). For this purpose, we employed MATLAB ${ }^{\circledR}$ R2013a. The patches were used for color test chart creation in Adobe ${ }^{\circledR}$ Illustrator $^{\circledR}$ CS6 software. The PDF file for printing was generated according to PDF/X-4 guidelines.

The created color test charts were printed on matte coated $300 \mathrm{~g} / \mathrm{m}^{2}$ paper using calibrated digital printing machine for XEROX Versant 80 Press (printing technique: electrophotography). According to recommendations for the short term repeatability (Ideaaliance, 2018) three sheets were printed for each sampling time: 0 hour (sheets 1), 1 hour after (sheets 2 ) and 24 hour after (sheets 3 ). The measurements were done on each sheet for each patch trice. The average values of 9 color measurements were used for color difference calculation. The colorimetric measurements were performed using Techkon SpectroDens Advanced spectrophotometer (measurement geometry: $0^{\%} / 45^{\circ}$ with respect to CIE D50 standard illuminant and standard $2^{\circ}$ observer). Measurement is performed on black, matte backing.

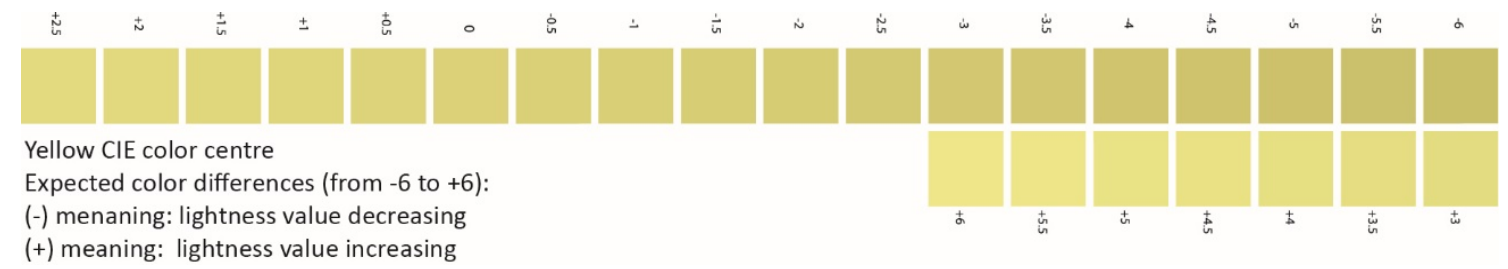

Figure 1: One part of the generated color test chart (one color-yellow)

For calculation of reproduced color difference, we used $\Delta \mathrm{E}_{00}$ (Stone et al, 2018):

$\Delta \mathrm{E}_{00}=\sqrt{\left[\left(\Delta \mathrm{L}^{\prime} / K_{L} S_{L}\right)^{2}+\left(\Delta \mathrm{C}^{\prime} / K_{c} S_{c}\right)^{2}+\left(\Delta \mathrm{H}^{\prime} / K_{H} S_{H}\right)^{2}+R_{T}\left(\Delta \mathrm{C}^{\prime} / K_{c} S_{c}\right)\left(\Delta \mathrm{H}^{\prime} / K_{H} S_{H}\right)\right]}$

where

$\Delta \mathrm{L}^{\prime}=L_{1}^{\prime}-L_{2}^{\prime}$

$\Delta \mathrm{C}^{\prime}=C-C_{2}^{\prime}$

$\Delta \mathrm{H}^{\prime}=2\left(C_{1}^{\prime} C_{2}^{\prime}\right)^{\frac{1}{2}} \sin \left(\Delta \mathrm{h}^{\prime} / 2\right)$

$\Delta \mathrm{h}^{\prime}=h_{1}^{\prime}-h_{2}^{\prime}$

$S_{L}=1+\frac{0.015\left(\overline{L^{\prime}}-50\right)^{2}}{\sqrt{20+\left(\overline{L^{\prime}}-50\right)^{2}}}$ 


$$
\begin{aligned}
& S_{c}=1+0.045 \overline{C^{\prime}} \\
& S_{H}=1+0.015 \overline{C^{\prime}} T \\
& T=1-0.17 \cos \left(\overline{h^{\prime}}-30^{0}\right)+ \\
& +0.24 \cos \left(2 \overline{h^{\prime}}\right)+0.32 \cos \left(\overline{3 h^{\prime}}+6^{0}\right)+0.20 \cos \left(\overline{4 h^{\prime}}+63^{0}\right) \\
& R_{T}=-\sin (2 \Delta \theta) R_{C} \\
& \Delta \theta=30 \exp \left\{-\left[\left(\overline{h^{\prime}}-275^{0}\right) / 25\right]^{2}\right\} \\
& R_{C}=2 \sqrt{\frac{\overline{\bar{C}^{\prime}}}{{\overline{c^{\prime}}}^{7}+25^{7}}} \\
& L^{\prime}=L^{*} \\
& a^{\prime}=(1+G) a^{*} \\
& b^{\prime}=b^{*} \\
& C^{\prime}=\left(a^{\prime 2}+b^{2}\right)^{1 / 2} \\
& h^{\prime}=\tan -1\left(b^{\prime} / a^{\prime}\right) \\
& G=0.5\left(1-\sqrt{\left.\frac{{\overline{C_{a b}^{*}}}_{\overline{C_{a b}^{*}}}^{7}+25^{7}}{G}\right)}\right. \\
& K_{L}=1 ; K_{c}=1 ; K_{h}=1 ; \text { default values. }
\end{aligned}
$$

Table 1: CIELAB chromaticity parameters of the test color centers (CIE1931 Standard Colorimetric Observer) (Xu et al, 2002)

\begin{tabular}{|l|l|l|l|l|l|}
\hline CIE color centre & $\mathrm{L}_{1}$ & $\mathrm{a}_{1}$ & $\mathrm{~b}_{1}$ & $\mathrm{C}_{1}$ & $\mathrm{~h}_{1}{ }^{\circ}$ \\
\hline Red & 44.38 & 36.91 & 23.33 & 43.67 & 32 \\
\hline Green & 56.09 & -32.13 & 0.44 & 32.13 & 179 \\
\hline Blue & 35.60 & 4.83 & -30.18 & 30.56 & 279 \\
\hline Yellow & 86.65 & -6.92 & 47.15 & 47.66 & 98 \\
\hline Gray & 61.65 & 0.11 & 0.04 & 0.12 & 20 \\
\hline
\end{tabular}

Short term repeatability was evaluated according to $\triangle E O 0$ values computed between all combinations of press sheets: sheets 1 ( 0 hour) and 2 ( 1 hour), sheets 1 ( 0 hour) and 3 (24 hours), and sheets 2 ( 1 hour) and 3 (24 hours) (Ideaaliance, 2018).

\section{RESULTS AND DISCUSSION}

On Figure 2a are presented calculated color differences $\left(\Delta \mathrm{E}_{00}\right)$ for red color. The straight line represents the ideal color reproduction, theoretically achievable targeted/ reproduced color difference ratio. According to the results, the color differences reproduced on the first and second set of prints exhibited moderate to large discrepancies from targeted values whereas reproduced color differences were of lower value for the whole range. The least deviations were observed on sheets 3 (printed after $24 \mathrm{~h}$ ). Color difference values calculated for the sheets 1 and sheets 2 are somewhat similar, where the deviations were higher if the targeted color difference value was higher too. On Figure $2 b-d$ are presented absolute differences in lightness and chromaticity coordinates. It can be noticed that the difference in chromaticity values take a share in overall color difference, although initially only lightness value of color patches was changed.

On Figure $3 a$ are presented calculated color differences $\left(\Delta E_{00}\right)$ for green color where the straight line represents the ideal reproduction. It can be seen that the color differences reproduced on all three sets of prints are reflecting smaller discrepancies from targeted values except for the prints 2 and values defined through lightness decrease. On Figure 3b-d are presented absolute differences in lightness and chromaticity coordinates. The difference in chromaticity values take a share in overall color difference, but in much lover range in comparison to the red color. 


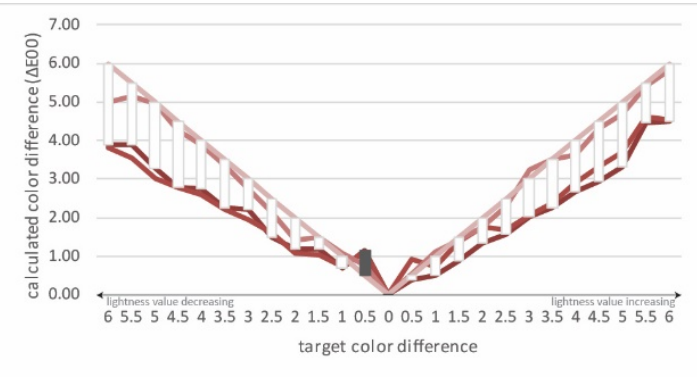

a)

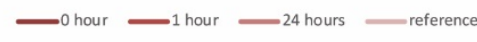

b)

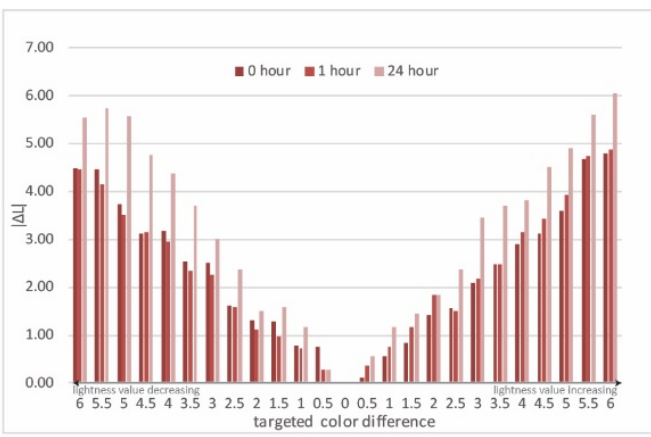

c)
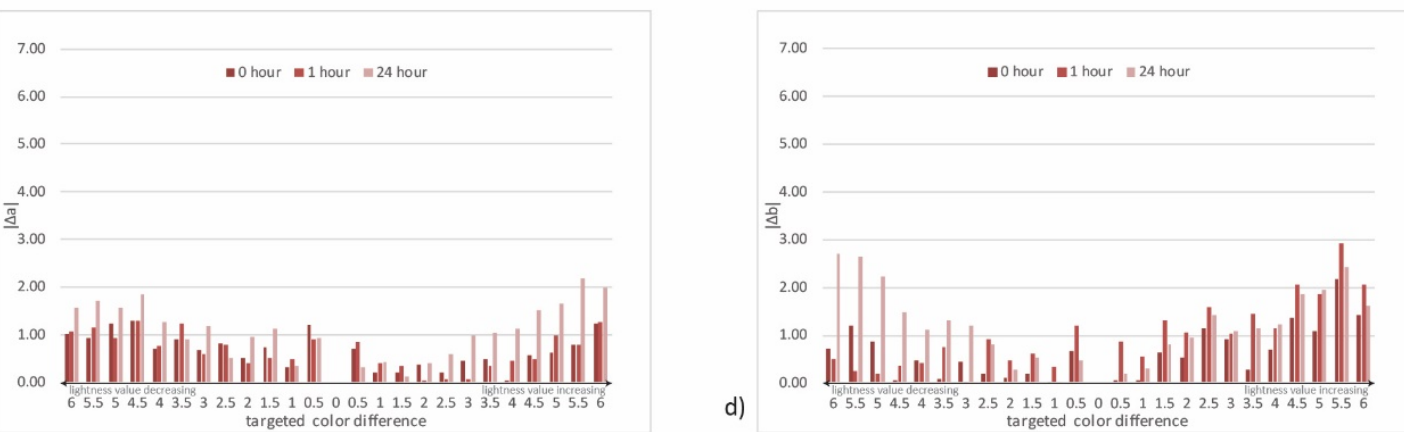

Figure 2: Red CIE color centre: a) color difference $\left(\Delta E_{00}\right)$, b) lightness difference (absolute values), c) difference in chromaticity coordinate a (absolute values), d) difference in chromaticity coordinate b (absolute values)

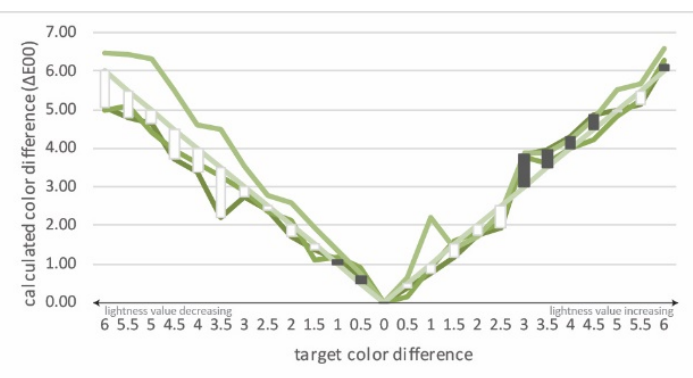

a)
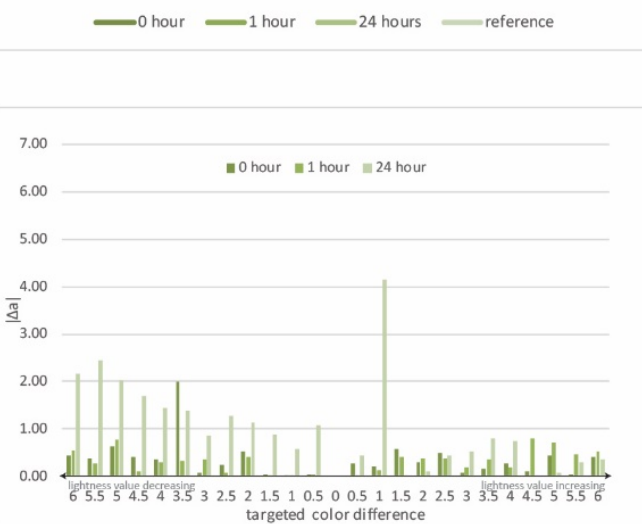

b)

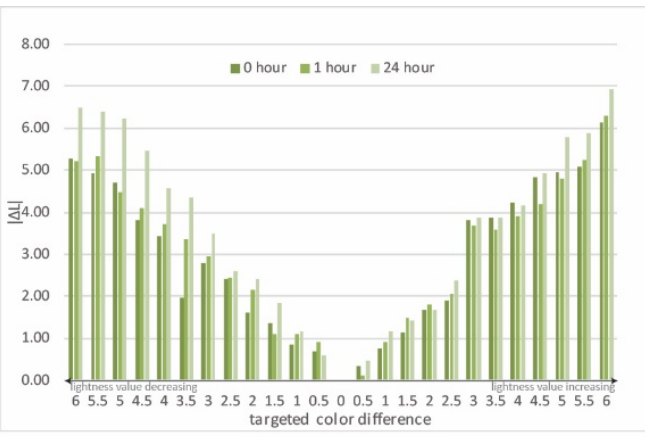

d)

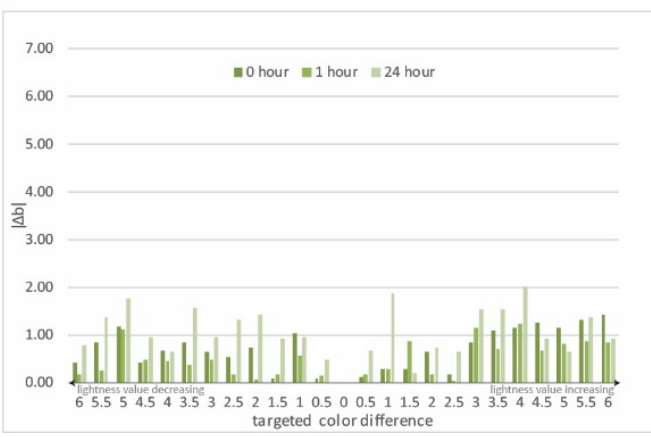

Figure 3: Green CIE color centre: a) color difference $\left(\Delta E_{00}\right)$, b) lightness difference (absolute values), c) difference in chromaticity coordinate a (absolute values), d) difference in chromaticity coordinate b (absolute values)

On Figure $4 a$ are presented calculated color differences $\left(\Delta \mathrm{E}_{00}\right)$ for blue color which exhibits the same pattern in color differences reproduction as the red color. On Figure $4 b-d$ the one can see the results of the absolute differences in lightness and chromaticity coordinates. It can be noticed that the difference in chromaticity values take a share in overall color difference, but in much lover range in comparison to the red color. 


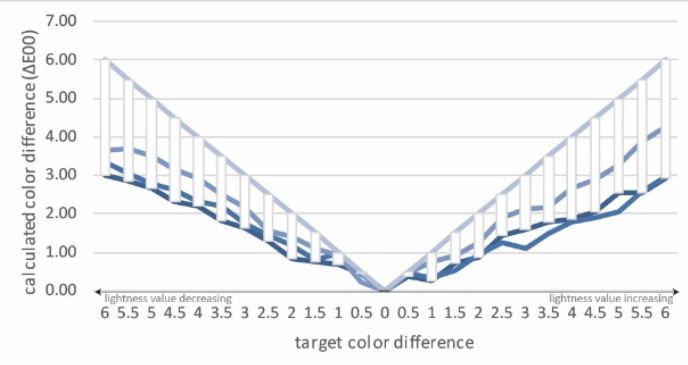

a)

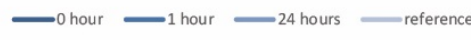

c)

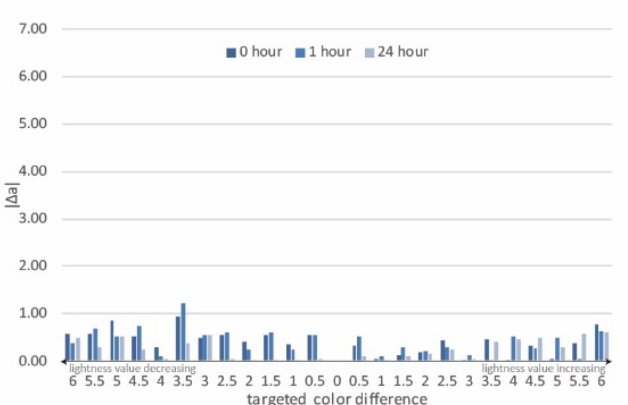

b)

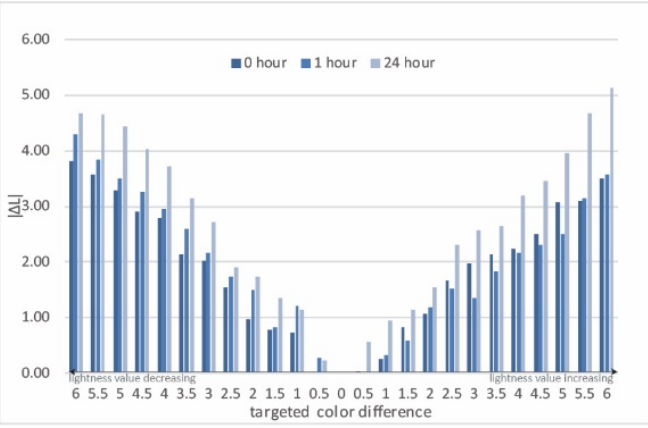

d)

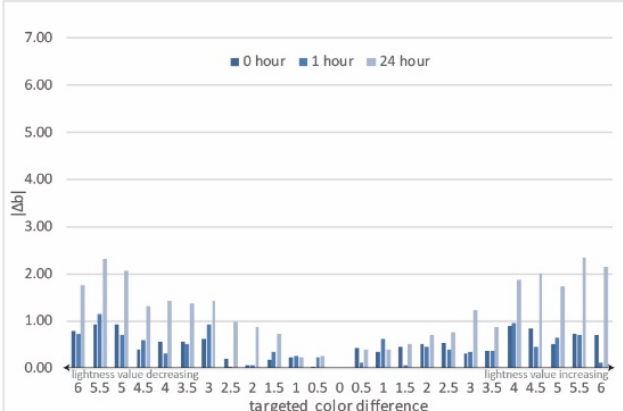

Figure 4: Blue CIE color centre: a) color difference ( $\left.\Delta E_{00}\right), b$ ) lightness difference (absolute values), c) difference in chromaticity coordinate a (absolute values), d) difference in chromaticity coordinate b (absolute values)

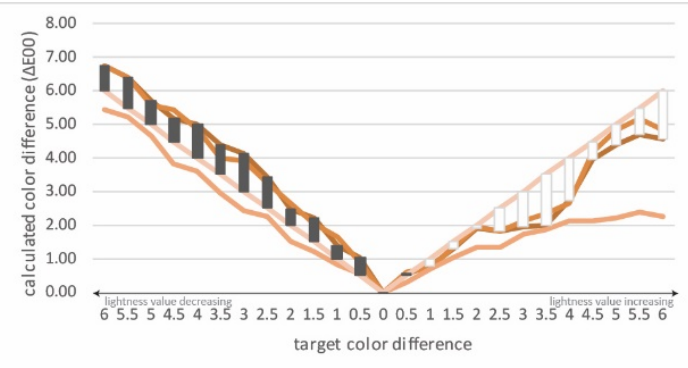

a)
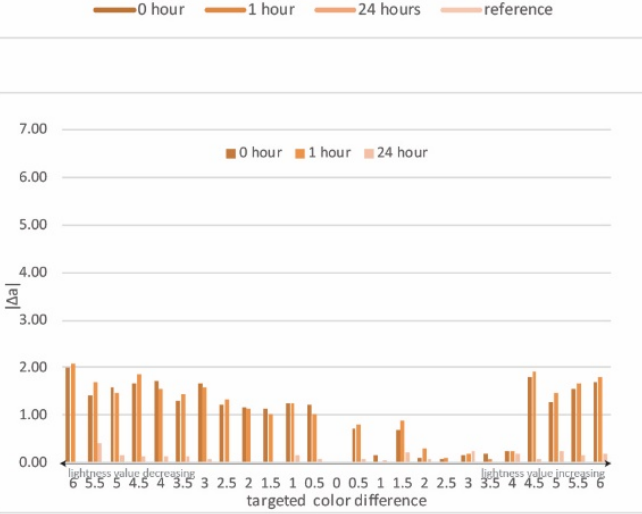

b)

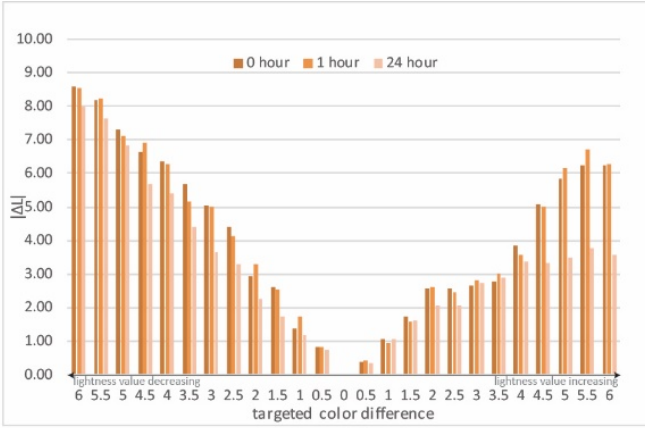

d)

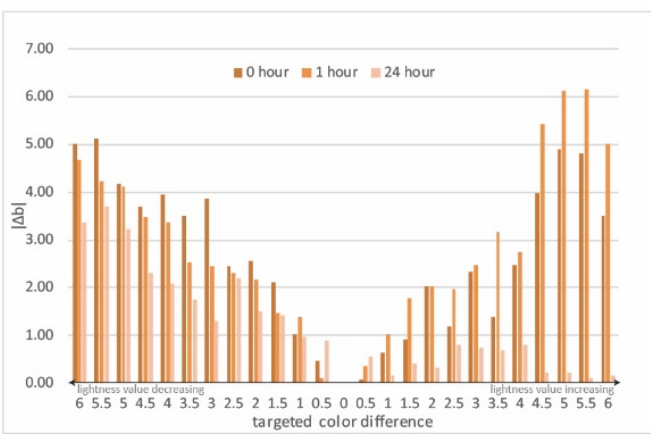

Figure 5: Yellow CIE color centre: a) color difference ( $\left.\triangle E_{00}\right)$, b) lightness difference (absolute values), c) difference in chromaticity coordinate a (absolute values), d) difference in chromaticity coordinate b (absolute values)

On Figure $5 \mathrm{a}$ are presented calculated color differences $\left(\Delta \mathrm{E}_{00}\right)$ for yellow color. It can be noticed color differences reproduction differs in dependence of sheet set as well as the fact if the lightness value was decreased or increased. The more accurate reproduction is achieved when the lightness value was decreased, especially in the case of sheets 3 (printed after 24 hours). On Figure 5b-d are presented absolute differences in lightness and chromaticity coordinates. It can be noticed that the difference in chromaticity values take a considerable share in overall color difference, especially in the case of chromaticity coordinate $b$. 


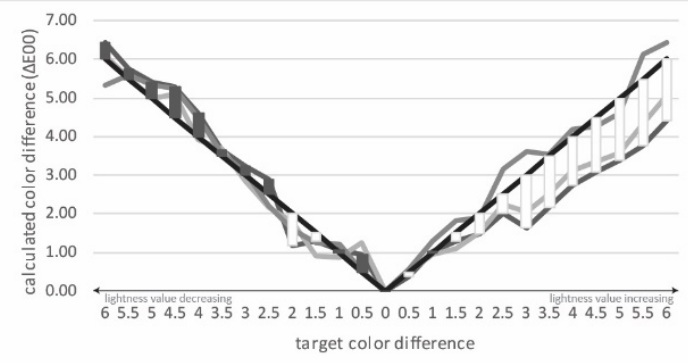

a)
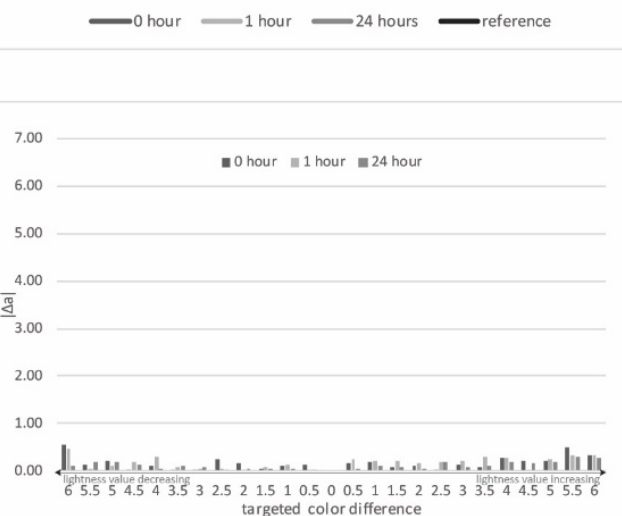

c) targeted color difference
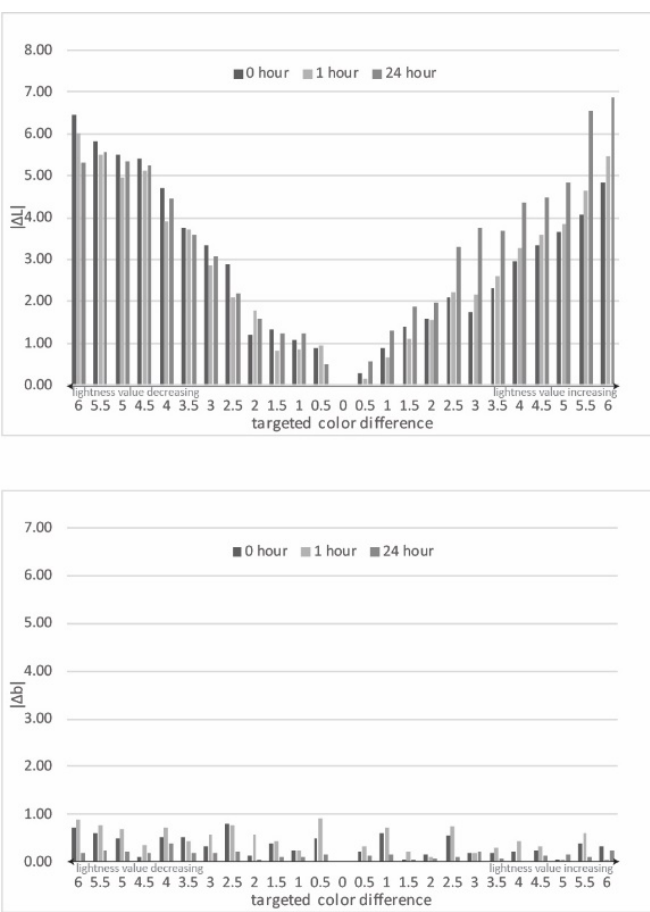

Figure 6: Gray CIE color centre: a) color difference ( $\left.\Delta E_{00}\right)$, b) lightness difference (absolute values), c) difference in chromaticity coordinate a (absolute values), d) difference in chromaticity coordinate b (absolute values)

On Figure 6a are presented calculated color differences $\left(\Delta E_{00}\right)$ for gray color which exhibit rather similar reproduction accuracy to yellow CIE color centre. The most accurate reproduction is achieved when the lightness value was decreased. On Figure $6 b-d$ are presented absolute differences in lightness and chromaticity coordinates. It can be seen that the difference in chromaticity values take a rather small part in overall color difference.

Table 2: Coefficient of variation (average value)

\begin{tabular}{|c|c|c|c|c|c|c|c|c|c|}
\hline \multicolumn{9}{|c|}{ Coefficient of variation (average value) (\%) } \\
\hline $\begin{array}{c}\text { CIE color } \\
\text { centre }\end{array}$ & \multicolumn{3}{|c|}{ 0 hour } & \multicolumn{3}{c|}{1 hour } & \multicolumn{3}{c|}{24 hours } \\
\hline & $\mathrm{L}$ & $\mathrm{a}$ & $\mathrm{b}$ & $\mathrm{L}$ & $\mathrm{a}$ & $\mathrm{b}$ & $\mathrm{L}$ & $\mathrm{a}$ & $\mathrm{b}$ \\
\hline Red & 0.70 & 1.11 & 2.31 & 0.71 & 1.10 & 2.35 & 0.72 & 1.06 & 1.22 \\
\hline Green & 0.95 & 1.51 & 6.22 & 0.66 & 0.92 & 8.80 & 0.49 & 2.25 & 8.80 \\
\hline Blue & 1.06 & 7.35 & 0.84 & 0.94 & 6.95 & 0.97 & 0.90 & 9.91 & 0.78 \\
\hline Yellow & 0.42 & 2.71 & 0.16 & 0.43 & 2.58 & 1.51 & 0.22 & 0.81 & 0.95 \\
\hline Gray & 0.97 & 11.48 & 10.66 & 0.97 & 11.03 & 9.88 & 0.80 & 4.89 & 3.94 \\
\hline
\end{tabular}

In Table 2 are presented results of the calculated coefficient of variation for $L$, a and b color coordinates, for all $\mathrm{CIE}$ color centres and all groups of sheets. According to the low coefficient of variation (varying from $0.22 \%$ up to $11.48 \%$, in dependence of color and sheet set), it can be stated that the measurement was stable and repeatable throughout all sheets in all three sets. The variation in $L$ value was under $1 \%$, while higher variations were between values of the chromaticity coordinates.

In Table 3 are given results of color difference calculations between sheets 1 ( 0 hour), 2 ( 1 hour) and 3 (24 hours). As it was in introduction section highlighted, upper tolerance for the short term repeatability assessment is restricted to color difference value of 3 . This request was not fulfilled in case of red, green and yellow $\mathrm{CIE}$ color centre and sheet set 1 and 2 in contrast to sheet set 3 . The highest deviation was calculated for the yellow color. 
Table 3: Color difference values between sheets 1 ( 0 hour), 2 (1 hour) and 3 (24 hours) ( $\Delta E_{00}$ )

\begin{tabular}{|c|c|c|c|c|c|c|c|c|c|c|c|c|c|c|c|}
\hline \multirow{4}{*}{$\begin{array}{l}\text { Measuring } \\
\text { field }\end{array}$} & \multicolumn{15}{|c|}{ CIE color centre } \\
\hline & \multicolumn{3}{|c|}{ Red } & \multicolumn{3}{|c|}{ Green } & \multicolumn{3}{|c|}{ Blue } & \multicolumn{3}{|c|}{ Yellow } & \multicolumn{3}{|c|}{ Gray } \\
\hline & \multicolumn{15}{|c|}{ Color difference $\triangle \mathrm{E} 00$} \\
\hline & $0 / 1$ & $0 / 24$ & $1 / 24$ & $0 / 1$ & $0 / 24$ & $1 / 24$ & $0 / 1$ & $0 / 24$ & $1 / 24$ & $0 / 1$ & $0 / 24$ & $1 / 24$ & $0 / 1$ & $0 / 24$ & $1 / 24$ \\
\hline 6 & 1.06 & 5.61 & 6.18 & 0.27 & 4.75 & 4.88 & 0.83 & 1.53 & 0.72 & 0.41 & 8.76 & 9.12 & 0.98 & 2.01 & 1.17 \\
\hline 5.5 & 0.73 & 6.02 & 5.98 & 0.70 & 4.59 & 4.66 & 0.62 & 1.83 & 1.26 & 0.49 & 8.65 & 8.94 & 1.12 & 2.76 & 1.70 \\
\hline 5 & 0.82 & 5.92 & 6.16 & 0.23 & 4.59 & 4.80 & 0.72 & 1.84 & 1.13 & 0.34 & 8.41 & 8.72 & 0.89 & 2.84 & 1.98 \\
\hline 4.5 & 1.07 & 5.82 & 6.27 & 0.62 & 4.54 & 4.94 & 0.67 & 1.80 & 1.24 & 0.68 & 8.66 & 9.25 & 1.18 & 2.85 & 1.74 \\
\hline 4 & 0.82 & 6.39 & 6.44 & 0.57 & 5.06 & 5.33 & 0.73 & 1.64 & 0.93 & 0.37 & 8.77 & 9.00 & 0.71 & 2.78 & 2.16 \\
\hline 3.5 & 0.86 & 5.75 & 5.90 & 1.77 & 4.59 & 4.73 & 0.70 & 1.83 & 1.37 & 0.13 & 8.79 & 8.73 & 1.40 & 2.86 & 1.48 \\
\hline 3 & 0.83 & 6.36 & 6.80 & 0.52 & 5.05 & 5.39 & 0.58 & 1.36 & 0.83 & 0.47 & 9.03 & 9.08 & 0.93 & 2.74 & 1.85 \\
\hline 2.5 & 1.00 & 5.92 & 6.23 & 0.35 & 5.03 & 5.16 & 0.55 & 1.48 & 1.07 & 0.28 & 8.30 & 8.57 & 0.67 & 2.40 & 1.78 \\
\hline 2 & 0.88 & 6.70 & 7.11 & 0.85 & 4.85 & 5.08 & 0.89 & 1.67 & 0.86 & 0.64 & 8.19 & 8.70 & 1.97 & 3.34 & 1.50 \\
\hline 1.5 & 0.83 & 6.34 & 6.86 & 0.26 & 4.86 & 5.11 & 0.49 & 1.56 & 1.13 & 0.33 & 8.18 & 8.38 & 0.89 & 2.89 & 2.00 \\
\hline 1 & 1.03 & 6.66 & 7.16 & 0.59 & 5.49 & 5.70 & 0.82 & 1.38 & 0.72 & 0.73 & 7.63 & 8.32 & 1.17 & 3.12 & 1.96 \\
\hline 0.5 & 0.67 & 6.59 & 7.07 & 0.56 & 5.29 & 5.75 & 0.71 & 1.38 & 0.87 & 0.41 & 7.44 & 7.76 & 1.48 & 2.60 & 1.36 \\
\hline 0 & 1.18 & 6.70 & 7.53 & 0.38 & 5.59 & 5.93 & 0.47 & 0.91 & 0.54 & 0.43 & 7.38 & 7.79 & 1.35 & 2.90 & 1.56 \\
\hline 0.5 & 0.80 & 6.62 & 6.90 & 0.58 & 5.34 & 5.72 & 0.48 & 1.02 & 0.91 & 0.38 & 7.27 & 7.59 & 1.26 & 2.17 & 1.09 \\
\hline 1 & 0.92 & 6.92 & 7.50 & 0.27 & 4.97 & 5.22 & 0.46 & 0.72 & 0.49 & 0.48 & 7.16 & 7.55 & 1.56 & 2.51 & 1.03 \\
\hline 1.5 & 0.77 & 6.80 & 7.16 & 0.23 & 5.43 & 5.29 & 0.66 & 0.93 & 0.77 & 0.49 & 6.97 & 7.27 & 1.60 & 2.41 & 1.03 \\
\hline 2 & 0.76 & 6.79 & 7.32 & 0.23 & 5.56 & 5.56 & 0.45 & 0.67 & 0.47 & 0.41 & 6.67 & 7.06 & 1.33 & 2.49 & 1.24 \\
\hline 2.5 & 1.15 & 6.87 & 7.53 & 0.22 & 5.54 & 5.74 & 0.65 & 0.82 & 0.70 & 0.44 & 6.63 & 6.91 & 1.23 & 1.90 & 1.21 \\
\hline 3 & 1.14 & 6.79 & 7.75 & 0.61 & 5.24 & 5.82 & 0.91 & 0.68 & 0.99 & 0.37 & 6.94 & 7.24 & 0.96 & 1.18 & 0.77 \\
\hline 3.5 & 1.08 & 7.36 & 7.60 & 0.62 & 5.35 & 5.60 & 0.65 & 0.64 & 0.84 & 0.43 & 7.13 & 7.05 & 1.08 & 1.63 & 1.01 \\
\hline 4 & 0.94 & 6.92 & 7.60 & 0.66 & 5.11 & 5.67 & 0.80 & 0.92 & 0.85 & 0.55 & 6.61 & 7.08 & 1.01 & 1.49 & 0.62 \\
\hline 4.5 & 0.80 & 7.04 & 7.49 & 0.97 & 5.80 & 6.10 & 0.59 & 0.77 & 1.22 & 0.52 & 5.74 & 5.91 & 1.20 & 1.70 & 0.90 \\
\hline 5 & 0.78 & 7.21 & 7.67 & 0.47 & 6.19 & 6.44 & 1.05 & 0.82 & 1.17 & 0.31 & 5.30 & 5.32 & 1.13 & 1.69 & 0.57 \\
\hline 5.5 & 1.05 & 6.61 & 7.12 & 0.26 & 5.93 & 5.92 & 0.35 & 1.07 & 1.38 & 0.26 & 5.28 & 5.20 & 0.80 & 0.68 & 0.72 \\
\hline 6 & 1.06 & 6.90 & 7.51 & 0.24 & 6.21 & 6.12 & 0.54 & 1.01 & 1.44 & 0.46 & 5.52 & 5.57 & 0.71 & 0.88 & 0.31 \\
\hline average & 0.92 & $6.54 *$ & $6.99 *$ & 0.52 & $5.24^{*}$ & $5.47^{*}$ & 0.65 & 1.21 & 0.96 & 0.43 & $7.42^{*}$ & $7.68^{*}$ & 1.14 & 2.27 & 1.31 \\
\hline
\end{tabular}

\section{CONCLUSIONS}

The presented research was conducted in order to investigate the possibilities of using electrophotography, digital printing technique, for the purpose of color difference evaluation. The conclusions derived were as follows:

- $\quad$ Presented results have shown that the expected accuracy in color differences reproduction was not obtained in all cases and for all colors used.

- The reproduction accuracy is dependent on whether the color difference was affected by initial variations in color lightness, in positive or negative direction, color itself as well as the time frame in which was printing exhibited (sets 1, 2 and 3).

- The variability in terms of color difference accuracy reproduction was also influenced by changes in chromaticity coordinates which were initially left unchanged. Their variations are assumably influenced by electrophotographic printing process. This is especially noticeable in the case of yellow color.

- In the case of three CIE color centres (yellow, red and green), the color difference value requested for successful short term repeatability was not achieved, although color difference between sheets 1 and sheets 2 were exceptional (less than 1). For yellow color, the highest deviation from the upper bound of tolerance was exhibited.

- Generally, the size of the initially defined color difference and the accuracy of reproduction is in inverse correlation.

- According to the coefficient of variation values, it can be stated that the measurement was stable and repeatable throughout the experiment thus did not influence the parameters used to evaluate reproduction accuracy or short term repeatability. 


\section{ACKNOWLEDGMENTS}

This work was supported by the Serbian Ministry of Science and Technological Development, Grant No.: 35027 "The development of the software model for improvement of knowledge and production in the graphic arts industry".

\section{REFERENCES}

[1] Brainard, D. H.: "Color Appearance and Color Difference Specification", (Elsevier, Amsterdam, 2003.), pages 191-216.

[2] Dedijer S., Tomić I., Spiridonov I., Boeva R., Jurič (Rilovski) I., Milić N., Đurđević S.: "Ink - jet imprints in just noticeable color difference evaluation", Bulgarian Chemical Communications, 49 (L), 140- 147, 2017.

[3] Fairchild, M.D.: "Color Appearance Models", (John Wiley \& Sons, Chichester, 2013)

[4] Gulrajani, M. L.: "Colour measurement principles, advances and industrial applications", (Great Abington Cambridge, UK, Woodhead Publishing Limited in association with The Textile Institute Abington Hall, Granta Park, 2010)

[5] Ho, K. M. R., Cui, G., Luo, M. R., Rigg, B.: "Assessing colour differences with different magnitudes", Proceedings of the Interim Meeting of the International Color Association, Brazil 2004, (Brazilian Color Association, Lisbon, 2004), pages 117-120.

[6] Hong, G., Luo, M. R.: "New algorithm for calculating perceived colour difference of images", The Imaging Science Journal, 54 (2), 86-91, 2006. doi.org/10.1179/174313106X98737.

[7] Ideaaliance: "Digital Press Certification Program", URL http://connect.idealliance.org/HigherLogic/System/DownloadDocumentFile.ashx?DocumentFileKey =ef430ae7-2fcc-cd3a-2ff3-eab28265eaa1, (last request: 2018-08-01)

[8] Laborie, B., Vienot, F., Langlois, S.: "Methodology for constructing a colour-difference acceptability scale", Journal of Ophthalmic and Physiological Optics 30 (5), 568-577, 2010. doi.org/10.1111/j.1475-1313.2010.00765.x.

[9] Mangine, H., Jakes, K., Noel, C.: "A Preliminary Comparison of CIE Color Differences to Textile Color Acceptability Using Average Observers", Color Research and Application 30 (4), 288-294, 2005. doi.org/10.1002/col.20124

[10] Ortiz-Jaramillo, B., Kumcu, A., Philips, W.: "Evaluating color difference measures in images", Proceedings of the 8thInternational Conference on Quality of Multimedia Experience, Lisbon 2016, (Instituto de Telecomunicações, Lisbon, 2016), pages 1-6.

[11] Pant, D.R., Farup, I.: "Riemannian Formulation of the CIEDE2000 Color Difference Formula", Proceedings of the 18th CIC: Color Science and Engineering Systems, Technologies, and Applications, San Antonio 2010, (Society for Imaging Science and Technology, San Antonio, 2016), pages 103-108.

[12] Pant, D.R., Farup, I.: "Riemannian formulation and comparison of color difference formulas", Color Research and Application 37(6), 429-440, 2012. doi.org/10.1002/col.20710.

[13] SpectraCal: "Visual Color Comparison: A Report on Display Accuracy Evaluation", URL http://www.spectracal.com/Documents/White\%20Papers/Visual\%20Color\%20Comparison.pdf, (last request: 2018-02-07).

[14] Stone, M., Szafir, D.A., Setlur, V.: "An Engineering Model for Color Difference as a Function of Size", URL https://research.tableau.com/sites/default/files/2014CIC_48_Stone_v3.pdf, (last request: 2018-02-07).

[15] Xin, J. H., Lam, C. C., Luo, M. R.: "Investigation of parametric effects using medium colour difference pairs", Color Research and Application 26 (5), 376-383, 2001. doi.org/10.1002/col.1053.

[16] Xu, H., Yaguchi, H., Shioiri, S.: "Correlation between visual and colorimetric scales ranging from threshold to large color difference", Color Research and Application 27(5), 349-359, 2002. doi.org/10.1002/col.10081. 


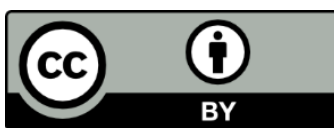

(C) 2018 Authors. Published by the University of Novi Sad, Faculty of Technical Sciences, Department of Graphic Engineering and Design. This article is an open access article distributed under the terms and conditions of the Creative Commons Attribution license 3.0 Serbia

(http://creativecommons.org/licenses/by/3.0/rs/). 